Hironori Iwasaki • Yasutomo Shinohara • Yoichi Ezura

Ryota Ishida • Mina Kodaira • Mitsuko Kajita

Toshiaki Nakajima • Tadayoshi Shiba - Mitsuru Emi

\title{
Thirteen single-nucleotide polymorphisms in the human osteopontin gene identified by sequencing of the entire gene in Japanese individuals
}

Received: March 26, 2001 / Accepted: May 10, 2001

\begin{abstract}
Osteopontin (OPN) is one of the major noncollagenous bone matrix proteins produced by osteoblasts and osteoclasts. We systematically surveyed the entire structure of the $O P N$ gene for single-nucleotide polymorphisms (SNPs) by directly sequencing 48 alleles derived from 24 unrelated Japanese individuals. We identified 13 SNPs in the $O P N$ gene. Ten polymorphisms were identified in introns 1,3 , and $5 ; 2$ in the coding region of exons 6 and 7; and 1 in the $3^{\prime}$ untranslated region of exon 7. Allele frequencies for some of the polymorphisms were significantly different from those reported in the United States National Center for Biotechnology Information (NCBI) dbSNP database. These polymorphisms will be useful in genetic studies to evaluate the role of OPN proteins in bone metabolism.
\end{abstract}

Key words Single-nucleotide polymorphism • Direct sequencing - Japanese population - Ethnic difference $\cdot$ Bone metabolism

\section{Introduction}

Osteopontin (OPN) is one of the major noncollagenous bone matrix proteins produced by osteoblasts and osteoclasts (Young et al. 1990; Reinholt et al. 1990). Genetic variation of the $O P N$ gene may predispose to bone loss and osteoporosis, because recent studies have suggested an as-

H. Iwasaki $\cdot$ Y. Shinohara $\cdot$ Y. Ezura $\cdot$ R. Ishida $\cdot$ M. Kodaira

M. Kajita $\cdot$ T. Nakajima $\cdot$ M. Emi $(\bowtie)$

Department of Molecular Biology, Institute of Gerontology,

Nippon Medical School, 1-396 Kosugi-cho, Nakahara-ku, Kawasaki

211-8533, Japan

Tel. +81-44-733-5230; Fax +81-44-733-5192

e-mail:memi@nms.ac.jp

Y. Shinohara $\cdot$ T. Shiba

Department of Molecular Biology, Kitasato University, Sagamihara, Japan sociation and linkage of certain genetic polymorphisms with determinants of bone mineral density and a predisposition to osteopenia and osteoporosis (Morrison et al. 1994). In the present study, we searched for single-nucleotide Polymorphisms (SNPs) by sequencing the entire $O P N$ gene in a panel of Japanese individuals.

\section{Materials and methods}

DNA extraction

Blood samples were obtained, with informed consent, from 24 healthy unrelated Japanese individuals. Genomic DNA was prepared from each sample according to the procedures described previously (Ikegawa et al. 1999).

Polymerase chain reaction (PCR) conditions and primer design

PCR and sequencing primers were determined by analyzing the genomic sequence with DNAsis 3.0 software (Hitachi Software Engineering, Tokyo, Japan). The sequence numbering was adjusted to the sequence of human DNA for osteopontin ( $\mathrm{G}$ at the top of $\mathrm{D} 14813$ is now +1$)$. PCR was performed as described previously, using genomic DNA (10ng) as a template (Tsukamoto et al. 1998). PCR amplification was performed under the following conditions: $94^{\circ} \mathrm{C}$ for $3 \mathrm{~min}, 72^{\circ} \mathrm{C}$ for $3 \mathrm{~min}$, then 5 cycles of $94^{\circ} \mathrm{C}$ for $30 \mathrm{~s}, 60^{\circ} \mathrm{C}$ for $30 \mathrm{~s}$, and $72^{\circ} \mathrm{C}$ for $30 \mathrm{~s}$, and 25 cycles of $94^{\circ} \mathrm{C}$ for $30 \mathrm{~s}, 58^{\circ} \mathrm{C}$ for $30 \mathrm{~s}$, and $72^{\circ} \mathrm{C}$ for $30 \mathrm{~s}$.

DNA sequencing

After affinity membrane purification, the PCR products were subjected to cycle sequencing with the appropriate primers, as described previously (Tsukamoto and Emi 1998). Differences in the sequences in the 24 samples were regarded as SNPs. 


\section{Results and discussion}

The entire genomic structure of the $O P N$ gene was sequenced in all 48 alleles from 24 unrelated Japanese individuals. We found a total of 13 SNPs with minor allele frequency geater than $4 \%$. The genomic structure and locations of the confirmed SNP sites are shown in Fig. 1. Ten of the 13 SNPs observed in the Japanese panel were intronic and novel.

Three SNPs in exon 6 and in exon 7 were archived in the United States database, i.e., the NCBI dbSNP database (http://www.ncbi.nlm.nih.gov/SNP/index.html) at the National Center for Biotechnology Information (NCBI) of the United States. The allele frequencies found in the present study were compared with those coding SNPs described in

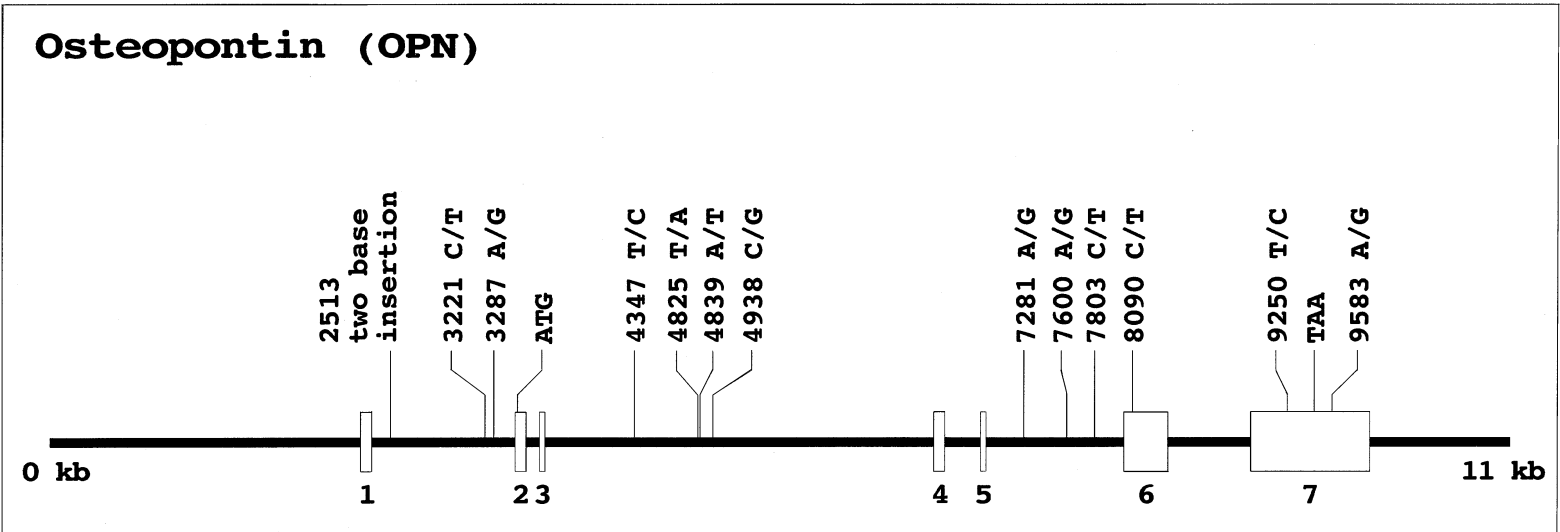

a

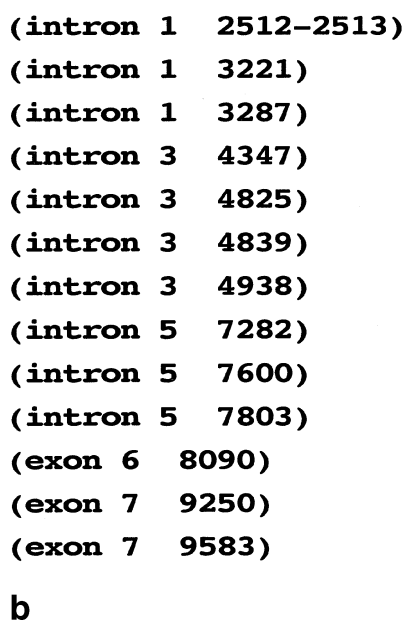

agatacattgcaggtctcct atacagacttgcaaaatttc aaatattaacttgaaagact ccagttgaacagaataaagg gtttttaaaaattataaatg taaatgaaacttatacatcc catctggtctcactgttttt aataagcatctaattaatgc ggaaagtggttatagatttt aatatctataaaaataattt atggatgatgaagatgatga agattatataagcggaaagc atttgagtctggaaataact

-/CA
$\mathbf{C} / \mathbf{T}$
$\mathbf{A} / \mathbf{G}$
$\mathbf{T} / \mathbf{C}$
$\mathbf{T} / \mathbf{A}$
$\mathbf{A} / \mathbf{T}$
$\mathbf{C} / \mathbf{G}$
$\mathbf{A} / \mathbf{G}$
$\mathbf{A} / \mathbf{G}$
$\mathbf{C} / \mathbf{T}$
$\mathbf{C} / \mathbf{T}$
$\mathbf{T} / \mathbf{C}$
$\mathbf{A} / \mathbf{G}$

gtggaacaaaggtgtctaga ctttcccttgcctaatagtg taatactaaaaagaaaaggc caaaatagagctgccttggg aacttatacatccttnctct tnctctctgagcctgtatta cgccttcttttttttttttt tatcaaagctaagattttgc gtacacacattaaaatatgg tgttgcaaagtaagaaatgt gaccatgtggacagccagga aatgatgagagcaatgagca atgtgtttgataattagttt

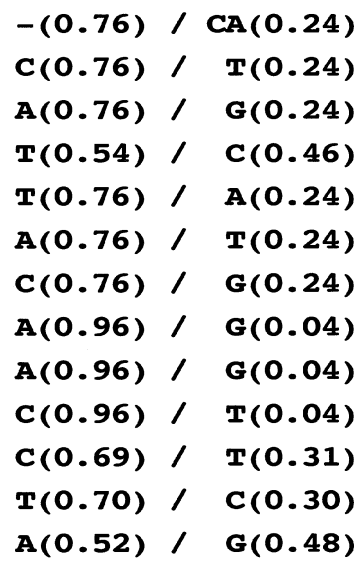

Fig. 1. a Genomic organization and locations of single-nucleotide polymorphisms (SNPs) in the osteopontin $(O P N)$ gene. Exons are represented by open rectangles. The guanine at the top of this sequence (UniSTS accession number, D14813) is denoted nucleotide +1 . b The

polymorphisms and the flanking sequences are listed, with the allele frequencies in the Japanese panel of individuals shown in the columns on the right, in parentheses

Table 1. Comparison of single-nucleotide polymorphisms in the $O P N$ gene in two populations

\begin{tabular}{llllll}
\hline Region & Position & Present study & $\begin{array}{l}\text { No. of } \\
\text { alleles }\end{array}$ & $\begin{array}{l}\text { NCBI db SNP } \\
\text { database }\end{array}$ & $\begin{array}{l}\text { No. of } \\
\text { alleles }\end{array}$ \\
\hline Exon 6 & 8090 & $\mathrm{C}(0.69) / \mathrm{T}(0.31)$ & 48 & $\mathrm{C}(0.24) / \mathrm{T}(0.76)$ & 38 \\
Exon 7 & 9250 & $\mathrm{~T}(0.70) / \mathrm{C}(0.30)$ & 48 & $\mathrm{~T}(0.39) / \mathrm{C}(0.61)$ & 38 \\
Exon 7 & 9402 & Monomorphic & 48 & $\mathrm{G}(0.93) / \mathrm{A}(0.07)$ & Not described \\
Exon 7 & 9583 & $\mathrm{~A}(0.52) / \mathrm{G}(0.48)$ & 48 & $\mathrm{~A}(0.78) / \mathrm{G}(0.23)$ & 74 \\
Exon 7 & 9690 & Monomorphic & 48 & $\mathrm{~A}(0.89) / \mathrm{C}(0.11)$ & 74 \\
Exon 7 & 9739 & Monomorphic & 48 & $\mathrm{~A}(0.71) / \mathrm{C}(0.29)$ & 76 \\
Exon 7 & 9760 & Monomorphic & 48 & $\mathrm{~A}(0.90) / \mathrm{C}(0.10)$ & 78 \\
Exon 7 & 9791 & Monomorphic & 48 & $\mathrm{~A}(0.94) / \mathrm{C}(0.06)$ & Not described
\end{tabular}

Frequencies are shown in parentheses

${ }^{a}$ The United States data were obtained from the NCBI dbSNP database at the National Center for Biotechnology Information (NCBI) of the United States (http://www.ncbi.nlm.nih.gov/SNP/) 
the United States database. Table 1 shows the results of this comparison of the SNPs of the OPN gene in the two populations. Only a minor portion of the SNPs observed in Japanese in the present study was observed in the United States database. The allele frequencies of the majority of the polymorphisms were significantly different from those reported in the United States database. We suspect that differences in SNP distribution and allele frequencies in the $O P N$ gene must exist among different ethnic groups. We recently observed major differences between Japanese and Caucasian populations with regard to the distribution and allele frequencies of SNPs in several other genes that are under investigation. These findings emphasize the ethnic differences in allele distribution among different human population, and indicate the necessity of analyzing genetic diversity in populations to be studied for specific disease association.

The deduced protein sequence of OPN shows a conserved cell attachment site arg-gly-asp that binds tightly to hydroxyapatite, and thus is involved in the anchoring of osteoclasts to bone matrix mineral (Young et al. 1990; Reinholt et al. 1990). OPN knockout mice are resistant to ovariectomy-induced bone resorption compared with wildtype mice (Yoshitake et al. 1999). In light of such recent progress in our understanding of the biological functions of $O P N$, the polymorphic sites characterized in the present study will serve as useful markers for examining the potential role of OPN proteins in bone metabolism and in the pathogenesis of osteoporosis in Japanese patients.
Acknowledgments This work was supported in part by a special grant for Strategic Advanced Research on "Cancer" and "Genome Science" from the Ministry of Education, Science, Sports, and Culture of Japan; by a Research Grant for Research from the Ministry of Health and Welfare of Japan; and by a Research for the Future Program Grant of The Japan Society for the Promotion of Science.

\section{References}

Ikegawa S, Isomura M, Koshizuka Y, Nakamura Y (1999) Cloning and characterization of human and mouse PROSC (proline synthetase co-transcribed) genes. J Hum Genet 44:337-342

Morrison NA, Qi JC, Tokita A, Kelly PJ, Crofts L, Nguyen TV, Sambrook PN, Eisman JA (1994) Prediction of bone density from vitamin D receptor alleles. Nature 387:284-287

Reinholt FP, Hultenby K, Oldberg A, Heinegard D (1990) Osteopontin - a possible anchor of osteoclasts to bone. Proc Natl Acad Sci USA 87:4473-4475

Tsukamoto K, Emi M (1998) A polymorphic CA repeat sequence at the human calcitonin locus. J Hum Genet 43:146-147

Tsukamoto K, Haruta K, Shiba T, Emi M (1998) Isolation and mapping of a polymorphic $\mathrm{CA}$ repeat sequence at the human interleukin 6 locus. J Hum Genet 43:71-72

Yoshitake H, Rittling SR, Denhardt DT, Noda M (1999) Osteopontindeficient mice are resistant to ovariectomy-induced bone resorption. Proc Natl Acad Sci USA 96:8156-8160

Young MF, Kerr JM, Termine JD, Wewer UM, Wang MG, McBride OW, Fisher LW (1990) cDNA cloning, mRNA distribution, heterogeneity, chromosomal location and RFLP analysis of human osteopontin (OPN). Genomics 7:491-502 